\title{
Anime-zing in North Carolina: Library Views of Anime Fans
}

A $s$ many people, especially young adult librarians, are well aware, Japanese cartoons and comics have become hugely popular in the last few years. Called anime and manga respectively, Japanese animation and Japanese comics are enjoying a huge surge in popularity.

But the current clamor about the popularity of anime actually hides a number of facts. Anime has certainly become a mainstream phenomenon. ${ }^{1}$ But it has been popular among devoted fans - sometimes but not always selflabeled as "otaku"- for years, and those fans span ages, genders, and interests. As with many forms of genre entertainment there is a whole fan culture surrounding the popularity of anime. Book clubs, viewing clubs, and collecting clubs form where otaku, or fans, read or watch and discuss their interests. Numerous online communities exist to discuss or expand on manga and anime series. And large conventions allow fans to gather and share their appreciation for the genre and related media. Fan conventions are an important part of anime and manga fan culture.

Publishers know the importance of fan conventions (or "cons") as a place to find the pulse of their audience with some saying they "need to be there for outreach and feedback from the fans." 2 The publisher exhibits at large fan conventions like San Diego Comic-Con go beyond simply exhibiting comics to related areas (such as video game hint books and reference books on comics) to broader areas such as audiobooks. ${ }^{3}$

If publishers find fan conventions to be a valuable place for outreach, the same can be true for libraries. Fan conventions can become a great way to understand and connect with users and non-users of libraries, as well as to market and outreach to an enthusiastic niche of readers.

\section{Anime and Libraries}

For libraries, there are several factors that make manga (and anime to a lesser extent) a topic of interest. The most obvious factor ties to an older debate about comics as a form of reading. Can manga be a way to interest reluctant readers in reading and libraries?

The school library at Currituck County High School certainly found that they could, when an LSTA grant caused them to survey their students' interests and wishes for the library. The students responded with extensive requests for graphic novels and manga. The resulting grant-funded purchase has enormously increased student visits to the library and kindled enthusiasm among the student body. ${ }^{4}$ Others have found that tying fan activities such as gaming, movies, and manga together with books can increase cross-platform interest. ${ }^{5}$

Manga and anime certainly attract and keep patron interest. Discussion of manga has been pervasive in the school, public, and young adult library literature. Libraries have found that manga readers can be hard to pin down and identify exact interests from ${ }^{6}$ but represent a motivated and stable user group even among adult patrons. ${ }^{7}$ Projects have focused on using local otaku and other fan clubs as a source of information and contact $^{8,9}$ which presents a strategy to either make contact with new patrons or harness a significant existing patron group. So getting involved in manga can be a draw for patrons and an outreach tool. Charbonneau's study ${ }^{10}$ of adult graphic novel enthusiasts - of which a notable number said they read manga only-came to the conclusion, "If you are considering creating a graphic novel collection in your library, build it and they will come!"

Another facet of interest to libraries is as a venue for programming. Showing anime movies can be a great program and has gotten especially popular as a way to attract teens. Some purists among anime fans also insist that the best way to enjoy anime is with the original Japanese voices and subtitles; this suggests a way to promote reading skills with anime. But even without this aspect, showing popular anime movies or establishing an anime club or screening schedule can attract enthusiasts to the library. Even more ambitious programming projects are cropping up in libraries with anime festivals combining fan gatherings with anime screenings, gaming, reading and discussion, panels, costuming, and more. ${ }^{11}$ These programs hinge on the popularity of fan gatherings in otaku culture as pivotal points for socialization, exchange of ideas, and contributing to the ebb and flow of fan culture.

\section{Fan Gatherings}

Part of the culture of being a fan of anime and manga is attending 
conventions, clubs, and other gatherings. Not all manga fans attend conventions of course, but many do. Librarians have described a related type of con, gaming conventions, as, " $[\mathrm{M}]$ ind-blowing for anyone who has never gone to one." ${ }^{\prime 2}$ The intensity of this kind of subculture gathering can surprise people who are new to the experience.

So what do these cons consist of? The idea is similar to other genre-oriented conventions, so it is generally centered on panels and signings. Fans watch screenings of anime shows both new and old, learn about forthcoming translations of manga, ask questions of authors and artists, and discuss the merits of various approaches used by the anime and manga industries, such as the ever-heated debate of whether to watch anime with subtitles or English voices.

Video games often play a large role, because in Japan there is regular interaction between media types, including games. Thus there are anime, manga, and novels which spawn off of games and games which spawn off of print and television media as well. Since they are inextricably linked it is common for fans to include video game rooms and discussions with other events at anime cons. Video game rooms host tournaments and players often stay up all night for group competitions or cooperative assaults on the game world. Performanceoriented game contests such as Dance Dance Revolution tournaments are popular because a watching crowd can enjoy them too.

Some of the practices at conventions might surprise people unfamiliar with anime fandom though. For example cosplay, or costume play, is an important con event for many fans. For some, the whole purpose of going to the con is to wear their costume or watch others in their costumes. Fans practicing cosplay, or 'cosplayers', most commonly dress up as a character from an anime, manga, video game, book, or other cultural source. Some cosplayers may dress up as original characters inspired by specific works; others may simply dress up in a style that is popular and evocative of manga or Japanese cultural themes. Costumes may be store-bought or combined from store-bought elements, but many serious devotees of cosplay insist on making their own costumes so that they can express their own image concept and not be restricted by a stock design. This kind of costuming can take many hours to work on. Posing for other fans' cameras and doing mini-skits in the hall gives cosplayers a chance to show off their great costumes and acting abilities. Cosplay contests, a perennial draw at conventions, therefore often include a brief amount of time for a skit. Specifically skit-oriented contests allow for longer, group skits. Cosplay contest prizes, often given by actors or artists from Japan or well-known U. S. anime voice actors, are coveted accolades.

There are usually some cultural events as well, such as Japanese traditional arts or music as well as modern Japanese or sometimes Korean popular music (J-pop and K-pop respectively). Because art is such an important part of manga, there is usually an amateur and early-career professional artists' area, or "artists alley", where fan artists sell and display their artwork. Art contests and similar events may draw amateur or early-career artists as well, and both aspiring and established online comic creators can often be found at cons selling books or drawings and promoting their web comics.

Amateur art is not the only commercial aspect. Fundraising or charity auctions are common events at cons, and there is always a Dealer's Room where businesses sell everything from expensive imported DVDs to Asian snacks and beverages.

There are too many types of events and features at anime cons to describe them all here. However, hopefully this summary will give the reader a few ideas of what it is like. The only way to really understand what a con is like is to attend one, and that is exactly what some librarians have done to get a better idea of their patrons' activities. Cons come in many sizes though, from small local ones with a hundred or fewer attendees to large international ones with thousands. There is a regional anime con in North Carolina based in the Triangle which draws fans from throughout the state and beyond called Animazement.

\section{Animazement}

The convention website says, "Animazement is an annual convention that celebrates the world of Japanese visual culture through anime, manga, video games, J-rock, martial arts, traditional crafts, and more! Brought to you by fans, for fans." Although it is a local gathering, it is not a small event. There are usually many international guests and it is normal to see guests, vendors, and artists from all over the country. Attendees come from all over the state as well as surrounding states and throughout the Southeast.

Over ten thousand attendees came to the Raleigh Convention Center for Animazement 2010. The 2009 $12^{\text {th }}$ Annual Animazement was the first to move to Raleigh having outgrown previous venues. The 2008 Animazement, at which this research was conducted, was the last one held in Durham, NC at the Sheraton Imperial hotel and convention center. Held on Memorial Day weekend, Friday through Sunday, Animazement is an event which many NC fans look 
forward to. Planning for each year begins as soon as the previous year ends, for the event coordinators as well as the fans, who often buy their tickets a year in advance to get discounted pricing.

The Wake County Public Library and other Triangle area libraries have a history of close involvement with Animazement. In the past this has included setting up library information booths and sponsoring contests. Since Animazement moved to the larger Raleigh Convention Center, Wake County Public Libraries have sponsored a manga reading room where fans can sit in relative quiet, relax, and read manga and magazines. This kind of embedded presence at the convention shows great teamwork and outreach with the fan community. The Wake system also built on that to develop programming in the library. ${ }^{13}$

\section{Other North \\ Carolina Gatherings}

It is worth mentioning that Animazement is not the only gathering for anime fans in the state. There are a number of other gatherings that include anime and manga fans as part of their attendees. Comic book conventions are a natural destination, especially for fans that particularly enjoy the manga side of things. North Carolina comic book conventions include Charlotte's HeroesCon as well numerous smaller "comicons" and related events in Raleigh, Charlotte, Boone, Sylvia, and elsewhere. Speculative fiction (i.e. science fiction and/or fantasy) conventions also regularly include some anime fans, due to the fact that there is an overlap between the two groups. In North Carolina there is a Triad regional speculative fiction convention called StellarCon, in Charlotte there is a NC/SC regional speculative fiction con called ConCarolinas, which always has an anime room, as well as smaller local events in several cities.

Smaller events also abound, often sponsored by colleges and cultural centers, such as Guilford College and the Asheville Art Museum and regional fan clubs. The college connection belies the idea of anime being a teen-only interest, as for many the interest persists into college years and beyond.

Smaller events and local fan clubs have also proved to be fertile ground for library outreach. Cumberland County Public Library hosts an annual "Librari-con" (information on the 2011 event is available at http://www.cumberland.lib. nc.us/teen/Libraricon/teens-LibrariCon2011.html), that partners with the anime and science fiction fans in the Fayetteville area and throughout the state. This "mini-con" is an amazing example of outreach to the niche community of serious enthusiasts, but also provides a fun program for library patrons who enjoy anime on a more casual basis. Similar efforts are being made, with a more general theme of science fiction rather than a specifically anime audience, by the Appalachian Regional Library (see http://www. facebook.com/pages/Wilkes-LibraryCon/170044036371372 for more information).

As with many things in North Carolina, outside of the largest cities people often feel that it is difficult to find events and gatherings of common interest. These smaller conventions represent efforts to remedy this lack and show the diversity of interests among the fan community. They also represent a great opportunity for programming, outreach, and better understanding of teen and adult fans.

\section{The Survey}

Data was gathered at the $11^{\text {th }}$ Animazement, which was held in Durham, NC, in 2008. Information was gathered by means of a survey administered in paper and online. To encourage participation, a raffle was included and signs were posted around the table encouraging participants. The table was located somewhat out of the main flow of traffic, but in an area where people often had to stand when waiting for events. Thus, bored people waiting in line would often take the survey for lack of anything else in particular to do.

Many participants self-identified as being involved in research in some way. A number of librarians, library workers, and people interested in libraries came by. Several students, including a number of graduate students, also came to take the survey. They self-identified as being interested in research and were sympathetic to the importance of good participation.

However, the majority of respondents came out of interest in the raffle or because they lacked anything better to do at the time. The raffle winner received a $\$ 25$ gift certificate to an online manga and anime retailer. Responses included an e-mail address for contacting the raffle winner, but data entry did not include collection of that item and the online questionnaire responses for this field were deleted as soon as the winner had collected the gift certificate code.

Young people who self-identified as being under 18 or who appeared to be minors were requested verbally to get their parents' permissions before filling out the survey and entering the raffle. However, most minors who approached the table were already in the company of an adult so this rarely presented a problem. It may have 
affected the response rate of younger persons though. Also, the number of questions may have been a deterrent to younger potential respondents.

Bias in the sample may therefore have come from several sources: higher participation from older attendees involved in research or libraries, length and parental requirements creating lower participation from younger attendees, geographic and timing effects due to the location of the table, and incentive-induced response bias ${ }^{14}$ that may have encouraged responses that were favorable towards the sponsor.

\section{Profile of a North Carolina Anime Fan}

There were 151 responses to the survey, of which 115 came from selfidentified North Carolina residents. For the purposes of this article, the results will be reported focusing on respondents from North Carolina only, for a total $n=115$. In both the paper and online versions there were no required responses. Any question that a respondent preferred not to answer was simply left blank; the survey administrators at the table encouraged anyone who expressed discomfort with a question that it was fine to write in something more appropriate or leave it blank as they preferred. Therefore not all response totals will add up to 115 .

The first information collected was general demographic information about gender, age, and school enrollment. Because one of the goals of this survey was to look at possible places of connection between anime fans and libraries, schools were thought to be an important aspect of where respondents might encounter libraries. Ages were roughly grouped according to broad school category as well. The option for "Other" was included for gender, but no North
Carolina respondents chose that option (see Table 1).

The next questions focused on broad relationships with libraries such as whether the individual had a library card, how often they used the library, and what types of libraries are being used. In the free response "other" field it should be noted that one patron mentioned ebooks as a library use, but did not include whether the source of the ebook subscription was public, school, workplace, or college. Because of the NC LIVE ebook holdings, ebook access can come from almost any library (see Table 2).

The next section discussed the uses of libraries by these anime fans.

\begin{tabular}{|l|c|c|c|}
\hline \multicolumn{1}{|c|}{ Demographic Traits } & Total & Female & Male \\
\hline Respondents in NC & 115 & 66 & 49 \\
\hline Ages 10-13 & 4 & 3 & 1 \\
\hline Ages 14-17 & 22 & 17 & 5 \\
\hline Ages 18-21 & 33 & 22 & 11 \\
\hline Ages 22-30 & 41 & 18 & 23 \\
\hline Ages 31 and over & 15 & 6 & 9 \\
\hline School enrollment: none & 34 & 13 & 21 \\
\hline Enrolled in Middle/Jr High & 4 & 3 & 1 \\
\hline Enrolled in & 25 & 18 & 7 \\
\hline High School & 20 & 11 & 9 \\
\hline Enrolled in community college & 31 & 21 & 10 \\
\hline Enrolled in college/university & & & \\
\hline
\end{tabular}

Table 1: Demographic Traits

\begin{tabular}{|l|c|c|c|}
\hline \multicolumn{1}{|c|}{ Library Patron Traits } & Total & Female & Male \\
\hline Library card holder & 88 & 58 & 30 \\
\hline Non-cardholder & 25 & 7 & 18 \\
\hline Cardholder: unsure/no response & 2 & 1 & 1 \\
\hline Library Use: Daily & 10 & 7 & 3 \\
\hline Library Use: Multiple times a week & 11 & 11 & 0 \\
\hline Library Use: Weekly & 15 & 12 & 3 \\
\hline Library Use: 2-3 per month & 15 & 10 & 5 \\
\hline Library Use: Monthly & 19 & 11 & 8 \\
\hline Library Use: Almost never & 37 & 11 & 26 \\
\hline Library Use: Never & 7 & 3 & 4 \\
\hline Uses public library & 89 & 54 & 35 \\
\hline Uses school library & 22 & 13 & $9 *$ \\
\hline Uses college library & 55 & 31 & 24 \\
\hline Uses workplace library & 6 & 3 & 3 \\
\hline * The survey should have been clearer on the nature of "school” libraries, as this \\
\hline exceeds the number of middle and high school enrollees for this category. \\
\hline
\end{tabular}

Table 2: Library Patron Traits
Directions indicated that participants should mark all appropriate categories. Results listed are ranked by overall percentage of how they are using libraries. Unsurprisingly, casual reading, school research, and homework were the most common uses of the library (see Table 3).

The next section asked respondents to rate their enthusiasm for different interests commonly found in the anime fan community. The activities rated were anime, manga, 'cosplay' or costume play, non-manga comics (which was included because library practices often group all graphic formats together), video games, and Japanese culture. 


\begin{tabular}{|l|r|r|r|}
\hline \multicolumn{1}{|c|}{ Library used for... } & Overall & $\begin{array}{c}\text { \% of } \\
\text { females }\end{array}$ & $\begin{array}{c}\text { \% of } \\
\text { males }\end{array}$ \\
\hline Casual reading & $66.0 \%$ & $70.3 \%$ & $59.5 \%$ \\
\hline Research for school & $59.4 \%$ & $64.1 \%$ & $52.4 \%$ \\
\hline Homework & $45.3 \%$ & $54.7 \%$ & $31.0 \%$ \\
\hline Meeting space & $25.5 \%$ & $29.7 \%$ & $19.0 \%$ \\
\hline $\begin{array}{l}\text { Other (non-school) } \\
\text { research }\end{array}$ & $23.6 \%$ & $18.8 \%$ & $31.0 \%$ \\
\hline Computer access & $23.6 \%$ & $25.0 \%$ & $21.4 \%$ \\
\hline $\begin{array}{l}\text { Book or manga } \\
\text { discussions }\end{array}$ & $14.2 \%$ & $21.9 \%$ & $2.4 \%$ \\
\hline $\begin{array}{l}\text { Library-sponsored } \\
\text { events }\end{array}$ & $10.4 \%$ & $12.5 \%$ & $7.1 \%$ \\
\hline Anime club meetings & $9.4 \%$ & $14.1 \%$ & $2.4 \%$ \\
\hline Anime screenings & $9.4 \%$ & $14.1 \%$ & $2.4 \%$ \\
\hline
\end{tabular}

Table 3: Library use by anime fans

\begin{tabular}{|l|r|r|r|}
\hline & \multicolumn{3}{|c|}{ Mean rating } \\
\hline Anime & 3.20 & 3.21 & 3.19 \\
\hline Manga & 3.05 & 3.26 & 2.75 \\
\hline Cosplay & 2.54 & 2.59 & 2.47 \\
\hline Comics & 2.18 & 2.19 & 2.17 \\
\hline Video Games & 3.21 & 3.14 & 3.29 \\
\hline Japanese Culture & 3.04 & 3.2 & 2.84 \\
\hline
\end{tabular}

Table 4: Enthusiasm for anime activities

\begin{tabular}{|c|c|c|c|}
\hline & Yes & No & Don't Know \\
\hline Does your public library carry anime? & $25 \%$ & $44 \%$ & $31 \%$ \\
\hline Does your public library carry manga? & $50 \%$ & $21 \%$ & $29 \%$ \\
\hline $\begin{array}{l}\text { Does your public library support fans in } \\
\text { other ways? }\end{array}$ & $14 \%$ & $20 \%$ & $66 \%$ \\
\hline $\begin{array}{l}\text { Does your school or college library } \\
\text { support fans in any way? }\end{array}$ & $19 \%$ & $32 \%$ & $49 \%$ \\
\hline
\end{tabular}

\begin{tabular}{|c|} 
What kind of anime/manga support would \\
you like to see at your public library?
\end{tabular}

Anime to check out

\begin{tabular}{l|l|l} 
Total & Female & Male
\end{tabular}

\begin{tabular}{|l|l|l|l|}
\hline Anime screenings & $77 \%$ & $77 \%$ & $76 \%$ \\
\hline
\end{tabular}

\begin{tabular}{|l|l|l|l|}
\hline Anime/manga club meetings & $48 \%$ & $47 \%$ & $49 \%$ \\
\hline
\end{tabular}

\begin{tabular}{|l|l|l|l|}
\hline Manga to check out & $70 \%$ & $71 \%$ & $67 \%$ \\
\hline
\end{tabular}

\begin{tabular}{|l|l|l|l|}
\hline Manga "book discussion" groups & $33 \%$ & $32 \%$ & $35 \%$ \\
\hline
\end{tabular}

\begin{tabular}{|l|l|l|l|l|}
\hline Manga art and business books & $37 \%$ & $44 \%$ & $29 \%$ \\
\hline
\end{tabular}

\begin{tabular}{|l|l|l|l|}
\hline All day fan or culture events & $40 \%$ & $41 \%$ & $39 \%$ \\
\hline
\end{tabular}

Table 6: Anime/manga wants at your public library

\begin{tabular}{|l|c|c|c|}
\hline $\begin{array}{c}\text { What anime/manga support would you } \\
\text { like to see in school/college libraries? }\end{array}$ & Total & Female & Male \\
\hline Manga to check out & $80 \%$ & $75 \%$ & $84 \%$ \\
\hline Manga discussions & $49 \%$ & $48 \%$ & $50 \%$ \\
\hline Graphic arts books & $61 \%$ & $67 \%$ & $52 \%$ \\
\hline Japanese language resources & $70 \%$ & $77 \%$ & $61 \%$ \\
\hline Japanese cultural information & $74 \%$ & $77 \%$ & $71 \%$ \\
\hline
\end{tabular}

Table 7: Anime/manga wants at your school/college library
Ratings were made on a Likert scale from 0 to 4: "No interest at all;" "My friends force me into it;" It's OK;" "I'm a huge fan;" and "Can't live without it" (see Table 4).

The next sets of questions were related to the intersection of libraries and anime interests. The first questions were related to library holdings and support for fan interests (see Table 5).

The next series of questions asked what fans would hope to see in public libraries, related to their anime fandom. An open-ended question for "other" was included as well as the closed-ended ones.

And the final group of questions was related to what support fans would like to see their school or college library provide for their anime fandom. The questions were intentionally skewed towards book resources and more scholastic materials. An open-ended question section followed, in which participants could make what comments they desired to the library community and express their ideas however they wanted.

\section{Discussion}

The demographics of the respondents were very different from what one might expect if focused on the image of cartoon-watching kids. Particularly notable was the fact that the largest group of respondents by age were from the 22-30 age group. The survey was designed with this group covering a relatively wide range of years on the assumption that it would be smaller than the young adult and college-age groups, but that was not the case. The college age 18-21 group was a large one with 33 respondents, but the 22-30 group was larger at 41 .

The gender balance was definitely towards the female, but not overwhelmingly so. The difference in library usage between female and male respondents was a more noticeable issue, with $88 \%$ of females having library cards compared to $61 \%$ of males. Whereas $78 \%$ of female respondents reported at least monthly use of a library, only 39\% of males reported at least monthly library use. Reassuringly, in both cases "almost never" using the library was much more likely than "never" using the library.

Most specific types of library uses had higher rates among females than males, which parallels the library patterns generally. It is also worth noting that contrary to what one might think, public libraries were more commonly reported to be used than 
school and college libraries combined. When asked, "What kinds of libraries do you use?" 77 respondents claimed they used a school or college library and 89 claimed they used a public library. That may explain why casual reading was the most common library use across both genders. Research for school was the second most common use in both genders and overall, with both uses being more popular for females than males. It is interesting to note, however, that male respondents had a much higher use of the library for nonschool-related research than females did. Non-school research tied with homework for third most popular use among males, though it was distinctly lower among females and when averaged overall (tied for fifth place overall, and seventh-most of the ten uses among females). One wonders if this is a particular trait of this fan group, or if personal research interests are a generally common library use for men. Fandom-related research interests could include cultural information, costuming techniques, video editing (for subtitling or for creating Anime Music Videos - AMVs - of anime clips set to music) and other technical study, art references, and many other possibilities.

An especially interesting set of results was in the fan interests questions. Although Animazement attendees might reasonably be assumed to like anime the best, the actual most popular interest was video games, with an average of 3.21 on a $0-4$ Likert scale. This edged out Anime with an average of 3.20, and was driven especially by male responses wherein over half responded that they "Can't live without it!!" on the topic of video games. Despite the fact that this is a convention of anime and Japanese culture fans, video games were notably the most popular activity. That not only gives us an insight into the multifaceted interplay of fan interests, it also suggests ways to cross-market library offerings.

Other interests were more predictably ranked. Anime was the next most popular, followed by manga and then Japanese culture. All of those averaged to above the "I'm a huge fan!" threshold (3 on the Likert scale) for the overall population. It is interesting to note that among male fans, Japanese Culture was more interesting than manga. For some fans, the manga version of a story is simply not interesting, and that may be an important insight into how to interest male anime fans. Perhaps cultural materials would be better resources for these fans.

It is also interesting to note that (non-Asian) comic books were the least popular interest across the board. This means that grouping graphic novels all together because they are all graphical is probably not an ideal browsing arrangement. Of course, much like the issue of whether or not to separate genres of fiction this is often a more practical choice than anything. But in a mythical 'ideal' browsing arrangement it appears that video games and cultural materials would be best shelved near the manga to catch readers' interests.

A brief question about what support existed at their libraries already was more complicated than had been expected. Not only were there, unsurprisingly, a great many "I don't know" responses to the question of whether manga and anime were available in the local libraries, there were definitely some erroneous "No" responses even in counties where there are robust anime programs. This leads one to wonder how fans could feel certain that there is no anime at a library that definitely has anime. This might be an outreach or marketing issue that could be addressed. In the course of collecting the data however, an interesting question arose. Several respondents asked "Does it count if all they have is ___? What the blank included varied between a few groups, the most common being the Disney versions of the Studio Ghibli movies such as Spirited Away or Howl's Moving Castle. Slightly less common were various children's television series Americanized from anime series, such as Pokemon or $Y u$ Gi Oh. The survey administrators consistently answered, "It's up to what you think, whether that counts or not," and some respondents verbally indicated they thought it did while others did not. This shows an interesting hierarchy of what is considered serious enough material to constitute real support.

The next section was about what fans would like to see in libraries in the way of fan support for anime fans and otaku interests. Because the overwhelming popularity of video games was not expected, the author had assumed that anime would be most popular, and then video games or manga would be second-most. Video game holdings and materials were not included in the prompting questions about what fans would like to see in libraries. It would be interesting in the future to incorporate more questions specifically on desired video game support.

Predictably, the idea of anime and manga to check out was the popular form of support that was hoped for at libraries, with anime being the most popular out of the list presented. Gatherings were a far less popular idea at public libraries, though anime screenings were a fairly popular idea among male respondents. Interestingly, there were some very 
strong wants from school libraries: the idea of Japanese language and cultural resources were very popular with $70 \%$ and $74 \%$ of respondents wanting to see such items in their school or college library. That level is on par with the idea of manga in public libraries, which also got 70\% support. Traditional "book talk" groups were the least popular idea in both categories, and the omnipresent "how to draw manga" style art and business books did not fare especially well either.

Open-ended responses to the question, "What would you like to see?" added some depth. There were only a few of these write-ins; most re-emphasized the existing responses with the desire for a greater quantity or variety of support. Some indicated that they were categorically not interested in anime or manga through the library. One surprising request suggested "Categorize according to content," implying that they wanted more robust genre cataloging. There were also specific interests voiced: anime music and all day events.

The general open-ended responses covered a greater range, but showed several specific trends. As in any population, there were several people who indicated that they were simply uninterested in the library. A number of further barriers of typical sorts occurred: distance, transportation issues, parking concerns, crowding, presence of vagrants, sense of indebtedness over past fines, lack of time, and both noise and quiet were all cited as barriers. Lack of need for the library was also a common factor with many people already having large book collections, but several also cited a sense that they were not welcome or wanted in the library and even that the staff was hostile to them. On the other hand, many respondents also expressed a deep love for the library and said that nothing could keep them away.

\section{Conclusion}

Perhaps the main thing that can be taken from this is that there is already a link between libraries and anime fans, but that it could be stronger. Carrying more manga and more anime could help, as well as outreach to ensure that these populations are aware of the library's interest in and acceptance of otakudom. There are thousands of anime fans in North Carolina and some libraries have found that the community is a great place to connect to patrons. Fans can be enthusiastic library supporters, once they get past the fear that they are unwanted by libraries.

There are also a wide variety of ways that libraries could fill the needs of this audience beyond merely carrying anime or manga. Consider video games, language, culture, costuming, art, and other related resources that may also appeal. They can provide a bridge between different interests, and show that the library understands that otaku culture extends beyond watching videos.

\section{References}

1 Jane Halsall, "Anime Goes Mainstream," School Library Journal 56, no. 9 (2010): 32-33.

2 Calvin Reid, "Publishers Find Fans and Trends at Comic-Con," Publishers Weekly, 2008, 4.

3 Ibid.

${ }^{4}$ Mary Simmons and Beth O’Briant, “Journey into the World of Manga and Graphic Novels,” Library Media Connection 27, no. 4 (2009): 16-17.

5 Rollie Welch, "From Platforms to Books? I’m Game,” Young Adult Library Services 6, no. 2 (2008): 30-31.

${ }^{6}$ Melissa Bergin, "Who Is Reading Manga?” Young Adult Library Services 3, no. 4 (2005): 25-26.

7 Olivier Charbonneau, "Adult Graphic Novels Readers," Young Adult Library Services 3, no. 4 (2005): 39-42.

8 Bergin, "Who Is Reading Manga?"

9 Tom Holman, “The Manga Club.” Bookseller (2006): 11-11.

${ }^{10}$ Charbonneau, "Adult Graphic Novels Readers," 40.

${ }^{11}$ Kelly Czarnecki, "Planning an Anime Fest," School Library Journal 56, no. 6 (2010): 20-21.; Nicole Lambert, "Library Anime Conventions for the Faint of Heart (and the Low on Cash)," Chapbook 66 (2009): 7-10.

${ }^{12}$ Paula Brehm-Heeger, Ann Conway, and Carrie Vale, "Cosplay, Gaming, and Conventions: The Amazing and Unexpected Places an Anime Club Can Lead Unsuspecting Librarians," Young Adult Library Services 5, no. 2 (2007): 14-16.

${ }^{13}$ Lambert, "Library Anime Conventions."

${ }^{14}$ Jeannine M. James and Richard Bolstein, "The Effect of Monetary Incentives and Follow-up Mailings on the Response Rate and Response Quality in Mail Surveys," Public Opinion Quarterly 54, no. 3 (1990): 346-61. 